\title{
Gamification in e-learning: The mitigation role in technostress
}

\author{
Faridiah Aghadiati Fajri ${ }^{1}$, RY. Kun Haribowo P. ${ }^{2}$, Nurisqi Amalia ${ }^{3}$, Dina Natasari ${ }^{4}$
}

${ }^{1,4}$ Accounting, Vocational College, Universitas Gadjah Mada, Yogyakarta, Indonesia

${ }^{2}$ Regional Economic Development, Vocational College, Universitas Gadjah Mada, Yogyakarta, Indonesia

${ }^{3}$ Property Management and Appraisal, Vocational College, Universitas Gadjah Mada, Yogyakarta, Indonesia

\section{Article Info}

Article history:

Received Nov 13, 2020

Revised Mar 4, 2021

Accepted Apr 15, 2021

\section{Keywords:}

E-learning

Gamification

Learning management system

Perceived playfulness

Technostress

\begin{abstract}
The digital world demands graduates who are accustomed to deal with technology. Blended learning is one of the strategies by combining online media with face-to-face classes. It cannot be denied that students who interact with technology experience stress and tension. This condition have an impact on the learning process so that a way out is needed to bring it down. Gamification is a gaming technique that is applied to non-game applications to increase pleasure when interacting with these applications. This feature has been implemented in business applications, social media, ecommerce, and e-learning. However, the impact of playfulness in mitigating technostress has not been studied. This research examined the role of feedback mechanism and presentation mechanism in giving pleasure in LMS. Furthermore, this playfulness is expected to reduce the stress experienced by users. The research was conducted using a quasi-experimental method by giving participants time to follow the course with the gamification feature. The results showed that the gamification mechanism is able to provide pleasure which in turn will reduce the user's stress level. Based on the userperceived of playfulness, gamification can reduce stress levels so it will reduce user resistance and increase the effectiveness of technology implementation.
\end{abstract}

This is an open access article under the CC BY-SA license.

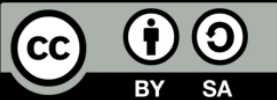

\section{Corresponding Author:}

Faridiah Aghadiati Fajri

Accounting, Vocational College

Universitas Gadjah Mada

Yogyakarta, Indonesia

Email: faridiahagha@ugm.ac.id

\section{INTRODUCTION}

In Human-Computer Interaction (HCI), users are expected to use the system to work efficiently [1]. Currently, the need to work online and collaborate using a platform requires users to adapt to new online media in a short time. The process of introducing digital media began during the education period. Blended learning requires the design of e-learning media that is able to spur the students to be tune in to the lesson plans. The current generation is digital millennials, so if you are treated to traditional e-learning, it will not be motivated. Technostress [2], [3] is something that cannot be avoided and must be managed so as not to reduce performance. Organizations must apply technostress management techniques because changes that very fast make users overwhelmed and resistant [4], [5]. Organizations try to provide support to mitigate technostress, one of which is using the gamification feature. Gamification has been developed in various systems, including learning systems.

Higher education is currently being challenged to meet demands for higher quality learning outcomes. The current era shows that internet information and communication technology is changing the 
way people live [6]. It cannot be left out that higher education must equip its graduates with digital abilities. The transformation of learning in the environment of higher education provides graduates with many benefits to face an increasingly electronic world [7]. Mixed learning has become a strategy for combining face-to-face teaching with online learning. This learning method is increasingly being used in education. Each discipline can take different forms depending on the course needs and the desired learning outcomes [8]. Higher education must ensure that blended learning does not completely replace face-to-face courses and keep the pace in using media running in line with the pace of lectures in the classroom. The digital world uses a combination of asynchronous and synchronous media. Synchronous media is used for meetings, coordination, interviews, discussions, to performance appraisals. Asynchronous media functions more as a platform in digital work for managing work, division of labor, monitoring, and evaluation. The demand to collaborate with other parts of the world makes work has no time limit. Digital work requires coordination with online meetings which leads to 'zoom fatigue' [9]. There are misconceptions about digital work, where there is not enough time for users to learn. This pressure makes digital work not lead to positive perceptions [10]. Also, additional pressure on work from home is followed by the consequence of online performance appraisal. Technostress [3] is something that cannot be avoided and must be well managed so as not to reduce performance. Organizations have to concern about technostress management techniques to avoid workers become overwhelmed and resistant [4], [5]. This condition can be managed by lowering the user's tension when interacting with asynchronous media.

The Learning Management System (LMS) has changed a lot from being a mere assignment system. Today, LMS functions a lot as an interactive communication platform. Improvements have been made in terms of features, appearance, communication to gain users' engagement. Gamification uses game elements so that at the same time playfulness elements also make it an ideal learning environment [11]. "Gaming" applications are currently being developed in various media although often the complexity is reduced to the simplest components, such as badges, levels, points, and leaderboards [12]. Burguillo [13] introduces a framework for using Game Theory tournaments as a basis for implementing Competition Based Learning $(\mathrm{CnBL})$. This framework is combined with other classical learning techniques with the aim of motivating students and increasing their learning achievement. This study not only discusses how the gamification feature increases student motivation but also the role of this feature in mitigating user technostress. The gaming features provide an experience that leverages students' motivation in learning management systems.

The learning management system concept used in this study assumes that there is no penalty for poor task performance. The principle of "freedom to fail" allows students to revise and resubmit assignments or reattempt quizzes with less than optimal results. This study also assumes that universities have implemented blended learning in their lectures because data collection was carried out at the time of the Covid-19 pandemic. This condition requires that all lectures be conducted using online media. Identifying the gamification mechanism is important to make online courses and MOOCs work effectively. This study aims to explore the feedback mechanism and determine the effect of this mechanism on the presentation mechanism. This scheme also aims to examine the impact of the two forms of game mechanisms on perceived playfulness. The results of the modelling in this study also identify the role of gamification features that can manage user stress. This study creates a more comprehensive model by starting with gamification elements, perceived playfulness in users, to the decrease in the level of technostress experienced by the Learning Management System (LMS) users. Mitigated user stress can reduce user resistance and increase the effectiveness of using the learning management system.

\section{LITERATURE REVIEW}

\subsection{Digital work}

Information technology that is driven by the needs of big data tends to be involved in the collaborative work area. The need for multi-platform interactions and interfaces to meet the need for realtime feedback on the collaboration [14]. The digital platform contributes to the control system management and the level of integration between components. The results of using digital platforms build an integrated environment that is able to share information from one office to another, track every action, determine the individuals involved and estimate the time needed to carry out a task. Besides, digital platforms differentiate interactions into information-sharing activities, collaborative activities, and collective activities [15], [16]. Software development with a digital platform is expected to be able to provide a more transparent flow of information, improve monitoring mechanisms, manage the budgeting process, analyze variants, and measure performance. This platform also allows integration with other software using the Open API so that the software can collaborate with various other software. 


\subsection{Gamification}

In essence, gamification is the application of game mechanisms in a non-game context. Gamification has been implemented in business, management, marketing, and social media for a long time, but gamification in education is still an emerging trend [17]. In the context of learning, gamification is applied in such a way that it does not change learning practices. Previous research has shown several gamification mechanisms. Codish and Ravid [18] suggests that the feature is classified into a feedback mechanism and a presentation mechanism. In the feedback mechanism, the gamification features are points, badges, and rewards, while the presentation mechanism uses a leaderboard and progress bar. Giving awards in the form of badges in online communities is a mechanism that can influence user behaviors [19]. This badge is given to a certain symbol of achievement. The user has to do the job up to the target or become an expert to earn a badge. Thus, badges are valuable things to earn. The reward feature is a way to reflect on students' achievements and reinforce their sense of competence and progress [12]. Denny [20] found that students enjoyed earning badges. Badges can indicate their contribution and indicate a strong preference for displaying them on the interface. Course completion preferences can be linked to the progress bar. Hence, badges can act as powerful motivators in an educational context.

\subsection{Technostress}

The development of Information Technology and Communication (ICT) has had a significant impact on the industrial sector. There is a demand for individuals to keep abreast of technological developments. This provides exposure in the form of pressure and concern for technology users who then feel unable to follow or accept technology. There are direct and indirect effects on technostress with a model of resistance to innovation [2], [21]. Users are expected to realize that the information technology application has benefits in helping their work. When users have IT awareness, the influence of technostress can be reduced and can increase user satisfaction in using the application [22], [23]. Technostress is a negative effect that arises in the process of implementing information technology [24]. The playfulness of gamification features offers to reduce user stress and tension. Stress caused by information technology may have a negative impact on technology acceptance or user productivity. An understanding of the learning management systems becomes crucial in this blended learning era. Gamification leads to a playful condition thus it can reduce the user tension. This condition will help students to achieve better knowledge transfer in the learning process.

Moreover, hypotheses of this research are:

H1: Feedback mechanism has a positive effect on the progress bar.

The leaderboard introduces a competitive layer on punctuality [25] and also serves to present progress or badges earned [18]. The leaderboard is the third most attractive gamification mechanism after virtual goods and redeemable points [26]. This indicates that there is competition among students on the individual leaderboard.

H2: Feedback mechanism has a positive effect on the leaderboard

Collection cards from our faculty and staff that students can receive in return for playful interactions [12]. 'Gamification' focuses on the playfulness nature of humans. This fun gamification feature can make users excited, boring tasks can be transformed into an interesting playing process [27]. Both the feedback mechanism and the presentation mechanism lead the user to the perceived playfulness of the system [18].

H3: The application of gamification to learning management system could enhance perceived playfulness H4: Perceived playfulness could reduce technostress

The feedback mechanism is analyzed for its impact on the presentation mechanism as well as both mechanisms on playfulness. This study aims to determine the mitigation role of playful conditions offered by LMS with the gamification feature. Figure 1 shows the conjecture of the variables in the model. In addition, this study examines the success of implementing this feature to manage user technostress.

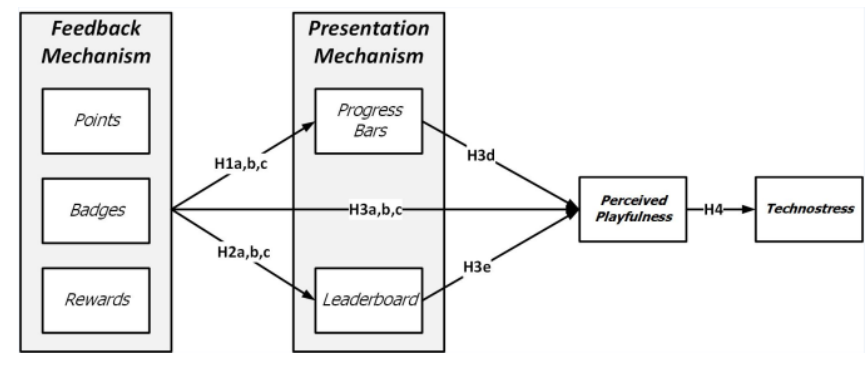

Figure 1. Proposed research model 


\section{RESEARCH METHOD}

The research model was tested using Structural Equation Modeling (SEM). The gamification mechanism in education was evaluated, and the effect of these features was examined. A quasi-experimental design was developed to investigate the effect of gamification in the Learning Management System (LMS). The LMS namely, eLok was the online course platform and Massive Online Open Course (MOOC) with Moodle for the gamification features. Table 1 contains the gamification features of the Moodle. The sample of the study was composed of 74 students in the third semester. Students who want to participate must have taken and passed intermediate accounting courses and actively used the eLok Learning Management System (LMS) for the past semester. Moddle's gamification features have been activated in the course, namely "It's Accounting!". The activated Moodle features are shown in Table 1.

Table 1. Moodle features

\begin{tabular}{lc}
\hline & Gamification \\
\hline XP Points & Earn XP for an activity \\
Badges & Obtained an award for mastering a skill \\
Level Up! & Acquisition of levels based on xp \\
Leaderboard & Ranking board \\
Progress Bar & Mission completion indicator \\
\hline
\end{tabular}

The implementation process starts with enrollment in the eLok. In the first step, students are asked to do a pretest quiz. Students cannot continue to another session before working on this pretest. The course runs for two weeks where students are free to access the material and work on the quizzes that have been provided. After completing the lesson, students were asked to do a post-test as a form of control in this quasiexperiment. Participants obtained several benefits after becoming participants in this research, including gaining access to accounting material, being able to measure skills in quizzes and tests, and having the opportunity to try gamification features that could be embedded in online learning media. In addition, students were asked to fill out questionnaires regarding gamification features, perceived playfulness, and technostress. In this process, students who complete all stages are 60 students.

Technology insecurity and technological uncertainty become irrelevant to the existence of a collaboration in cyberspace that has become a natural thing. Digital work allows work to be done anywhere even at home so that technology invasion is certain to occur and is no longer a stressor. 'Zoom fatigue' [9] which is attached to digital work is often the result of techno-overload and techno-complex. Techno-creators in the Transaction-Based model [3] can not be fully adopted in the scope of digital work. The construct which is showed in the Table 2 was analyzed by Smart PLS software. The first stage was algorithm run which is carried out to assess whether the data meets the assumptions of validity and reliability. This assessment is done by looking at the outer loading for each question item. In general, the threshold used for factor analysis with loadings of less than 0.5 should be drop [28]. Then, it is continued by assessing Average Variance Extracted (AVE), Composite Reliability, and Cronbach's Alpha. Composite reliability in exploratory research, 0.6 or higher is acceptable and AVE should be 0.5 or higher [29].

Table 2. Operational definition

\begin{tabular}{llcc}
\hline \multicolumn{1}{c}{ Constructs } & \multicolumn{1}{c}{ Operational definition } & Items & Source \\
\hline Points & Perception of the number of points obtained in online learning media & 2 & Codish and \\
Badges & Perceptions of badges or badges obtained in online learning media & 5 & Ravid [18] \\
Rewards & Perception of rewards obtained in online learning media & 4 & 4 \\
$\begin{array}{l}\text { Progress Bars } \\
\text { Leaderboard }\end{array}$ & Perception of the status of the progress bars displayed in online learning media & 6 & \multirow{2}{*}{ Moon and } \\
$\begin{array}{l}\text { Perceived } \\
\text { playfulness }\end{array}$ & Perception of leaderboard status displayed in online learning media & 9 & Kim [30] \\
Techno-overload & Individual perceptions that explain intrinsic behavior to be motivated & Ragu-Nathan, \\
Techno-complexity & A situation where technology forces users to work faster for a longer duration & 5 \\
& A situation where technology forces users to spend time and make an effort to & 5 & et al. [3] \\
& learn it & & \\
\hline
\end{tabular}

Furthermore, the bootstrapping stage is carried out to test the path of this research model. The significance level in the inferential analysis was considered to be .05 . The structural model analysis (inner model) was conducted to determine the relationship between variables, the significance value, and the Rsquare value. The structural model analysis in this study consists of 4 equations, namely: 1) The effect of the feedback mechanism on the progress bar; 2) The effect of the feedback mechanism on the leaderboard; 
3) The effect of all game mechanisms (points, badge, reward, progress bar, and leaderboard) on perceived playfulness; and 4) The effect of perceived playfulness on technostress users. These equations are as:

$$
\begin{aligned}
& P R O=\gamma P O I+\gamma B A D+\gamma R E W+\varsigma \\
& L E A=\gamma P O I+\gamma B A D+\gamma R E W+\varsigma \\
& P L A=\gamma P O I+\gamma B A D+\gamma R E W+\gamma P R O+\gamma L E A+\varsigma \\
& T S R=-\gamma P L A+\varsigma
\end{aligned}
$$

\section{RESULTS AND DISCUSSION}

These results are processed data obtained in a quasi-experimental process. The experiment included 75 students. The complete data was 60 and were included in the final analysis in a percentage of $80 \%$. Participants consisted of 46 females and 14 males aged 18-20 years. Descriptive statistics of the measure's value are presented in Table 3.

According to Fornell and Bookstein [31], the convergent validity should satisfy the conditions of factor loading $(\lambda)$, being significant and larger than 0.5. Factor loading has been checked for all items and requires removing four question items in the construct of perceived playfulness and the items was presented in Table 4. Convergent validity examination has been carried out for the existing full models and subsets as shown in Table 5.

Table 3. Descriptive statistics

\begin{tabular}{lccccc}
\hline \multicolumn{1}{c}{ Construct } & Items & Min & Max & Mean & Std. Dev. \\
\hline Point (POI) & 2 & 5 & 10 & 7.85 & 1.23 \\
Badge (BAD) & 4 & 7 & 20 & 13.18 & 2.56 \\
Reward (REW) & 4 & 10 & 20 & 14.77 & 2.20 \\
Leaderboard (LEA) & 6 & 6 & 30 & 21.15 & 4.03 \\
Progress Bar (PRO) & 4 & 12 & 20 & 16.32 & 1.95 \\
Perceived Playfulness (PLA) & 5 & 14 & 25 & 18.80 & 2.42 \\
Technostress (TSR) & 5 & 8 & 19 & 12.38 & 2.57 \\
\hline
\end{tabular}

\begin{tabular}{|c|c|c|c|c|c|c|c|c|c|c|}
\hline \multicolumn{4}{|c|}{ Reliability \& validity } & \multicolumn{7}{|c|}{ Factor correlations } \\
\hline Construct & Composite reliability & Cronbach's alpha & AVE & BAD & LEA & PLA & POI & PRO & REW & TSR \\
\hline $\mathrm{BAD}$ & .85 & .77 & .60 & 1.00 & & & & & & \\
\hline LEA & .91 & .89 & .64 & .68 & 1.00 & & & & & \\
\hline PLA & .88 & .83 & .60 & .11 & .42 & 1.00 & & & & \\
\hline POI & .87 & .71 & .77 & .41 & .44 & .26 & 1.00 & & & \\
\hline PRO & .89 & .83 & .67 & .55 & .68 & .33 & .50 & 1.00 & & \\
\hline REW & .86 & .79 & .61 & .41 & .49 & .40 & .50 & .52 & 1.00 & \\
\hline TSR & .86 & .80 & .55 & $\begin{array}{l}.71 \\
-.18\end{array}$ & -.14 & -.31 & -.33 & -.18 & -.31 & 1.00 \\
\hline
\end{tabular}

Table 4. Factor loading

\begin{tabular}{llcccc}
\hline \multicolumn{1}{c}{ Construct } & Items & Factor loadings & Construct & Items & Factor loadings \\
\hline Point (POI) & POI1 & .928 & Progress Bar (PRO) & PRO1 & .777 \\
Badge (BAD) & POI2 & .818 & & PRO2 & PRO3 \\
& BAD1 & .809 & & PRO4 & .857 \\
& BAD2 & .782 & Perceived Playfulness (PLA) & PLA4 & .730 \\
& BAD3 & .708 & & PLA6 & .702 \\
Reward (REW) & BAD4 & .785 & & PLA7 & .834 \\
& REW1 & .710 & & PLA8 & .847 \\
Leaderboard (LEA) & REW2 & .758 & Technostress (TSR) & PLA9 & .779 \\
& REW3 & .823 & & TSR1 & .715 \\
& REW4 & .837 & & TSR2 & .765 \\
& LEA1 & .779 & & TSR3 & .767 \\
& LEA2 & .726 & & TSR5 & .725 \\
& LEA3 & .795 & & & .744 \\
\hline
\end{tabular}

Table 5. Latent variable correlations 
Composite reliability and Cronbach's Alpha value are above the desired 0.7 indexes and AVE should be 0.5 or higher. Table 5 illustrates the composite reliability ranged from 0.86 to 0.91 and the composite reliability was higher than the 0.7 thresholds for each construct. Cronbach's $\alpha$ is greater than 0.7 , which means that every construct could be considered reliable. The Average Variance Extracted (AVE) ranged between 0.55 and 0.77 . The table showed that the lowest AVE was Technostress at 0.55. Thus, convergent validity was acceptable [29]. $\mathrm{R}$ square values for endogenous latent variables in the structural model of 0.75 can be described as substantial, 0.50 as moderate, or 0.25 as weak [32]. $R$ Square $\left(\mathrm{R}^{2}\right)$ to estimate the explanatory power of the model, where the larger $\mathrm{R}^{2}$ indicates the better explanatory power of the model. The determination of goodness of fit from the inner model evaluation is determined based on the R-square value (coefficient of determination) of endogenous variables.

$$
\begin{aligned}
& Q^{2}=1-(1-0.528)(1-0.299)(1-0.445)(1-0.098) \\
& Q^{2}=1-(0.472)(0.701)(0.555)(0.902) \\
& Q^{2}=0.834
\end{aligned}
$$

The calculation result of Q-square predictive relevance of 0.834 shows that $83.4 \%$ of the diversity of endogenous variables can be explained by the model formed. According to Figure 2, the total variance $\mathrm{R}^{2}$ value for the progress bar, leaderboard, perceived playfulness, and technostress were 44.5, 52.8, 29.9, and 9.8 percentage of the variance. Additionally, by examining how the model fits, $\mathrm{R}^{2}$ values show that almost $44.5 \%$ of the variance in the progress bar is contributed by point, badge, and reward, meaning that all feedback mechanism affects the progress bar. The $\mathrm{R}^{2}$ values for the leaderboard mean that almost $53 \%$ of the variance is contributed by point, badge, and reward. The result indicates that the model has a medium level of explanatory level. $\mathrm{R}^{2}$ values show that $29.9 \%$ of the variance in perceived playfulness is contributed by the feedback mechanism and presentation mechanism.

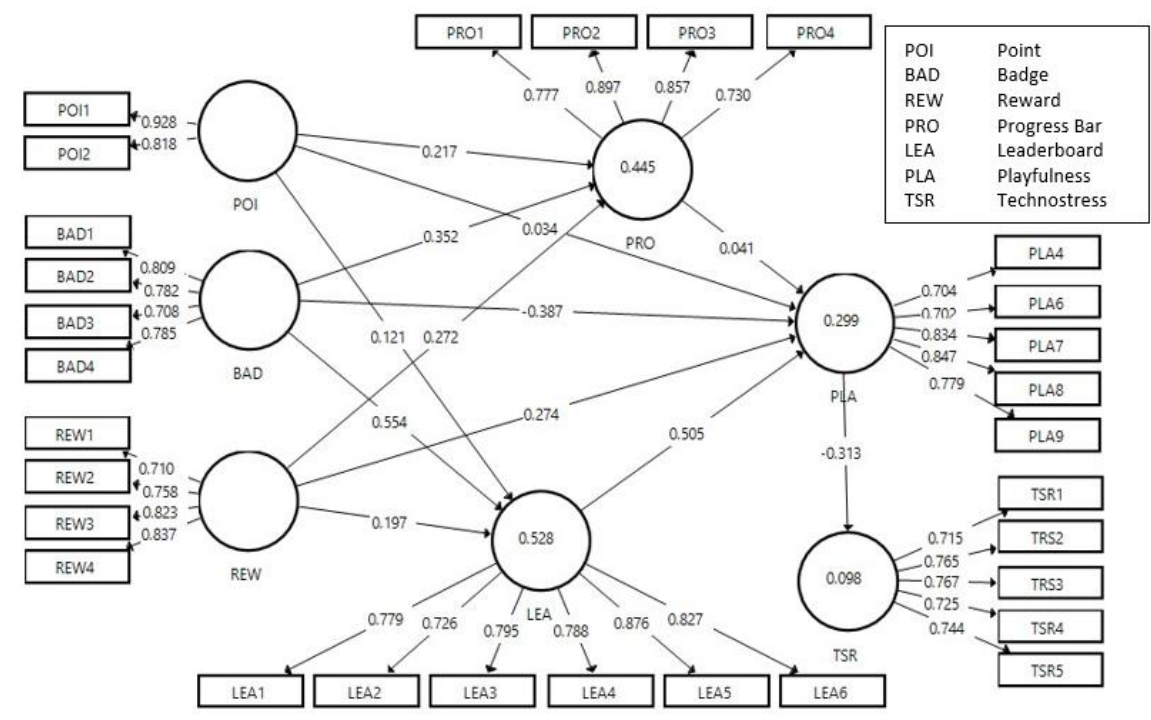

Figure 2. Result of the proposed research model

In this study, the structural model, and the relationship between the various aspects of the path coefficients and test results are shown in Table 6 . The equations are as:

$$
\begin{aligned}
& P R O=.217 P O I+.352 B A D+.272 R E W+\varsigma \\
& L E A=.121 P O I+.554 B A D+.197 R E W+\varsigma \\
& P L A=.034 P O I-.387 B A D+.274 R E W+.041 P R O+.505 L E A+\varsigma \\
& T S R=-.313 P L A+\varsigma
\end{aligned}
$$




\begin{tabular}{|c|c|c|c|}
\hline Hypothesis & T statistics & Path coefficients & R square \\
\hline Point $\rightarrow$ Progress bar & 1.822 & $.217 *$ & \\
\hline Badge $\rightarrow$ Progress bar & 2.565 & $.352 * *$ & .445 \\
\hline Reward $\rightarrow$ Progress bar & 2.017 & $.272 * *$ & \\
\hline Point $\rightarrow$ Leaderboard & 0.966 & .121 & \\
\hline Badge $\rightarrow$ Leaderboard & 4.980 & $.554 * * *$ & .528 \\
\hline Reward $\rightarrow$ Leaderboard & 2.056 & $.197 *$ & \\
\hline Point $\rightarrow$ Perceived playfulness & 0.180 & .034 & \\
\hline Badge $\rightarrow$ Perceived playfulness & 2.258 & $-.387 * *$ & \\
\hline Reward $\rightarrow$ Perceived playfulness & 2.199 & $.274 * *$ & .299 \\
\hline Progress bar $\rightarrow$ Perceived playfulness & 0.205 & $.041 * *$ & \\
\hline Leaderboard $\rightarrow$ Perceived playfulness & 2.545 & $.505 * *$ & \\
\hline Perceived playfulness $\rightarrow$ technostress & 2.806 & $-.313 * * *$ & .098 \\
\hline
\end{tabular}

The result showed that point, badge, and reward as the feedback mechanism has a positive effect on the progress bar $\left(\beta \mathrm{POI}=.217^{*}, \beta \mathrm{BAD}=.352^{* *}, \beta \mathrm{REW}=.272^{* *}\right)$, hence supporting $\mathrm{H} 1$. The result confirmed $\mathrm{H} 2 \mathrm{~b}$ and $\mathrm{H} 2 \mathrm{c}$, badge and reward were found to be predictors of the leaderboard $(\beta \mathrm{BAD}=.554 * * *$, $\beta \mathrm{REW}=.197 *)$, while the points $(\mathrm{H} 2 \mathrm{a})$ are not proven. All presentation mechanisms are able to predict perceived playfulness $\left(\beta \mathrm{PRO}=.041^{* *}, \beta \mathrm{LEA}=.505^{* *}\right)$, while the feedback mechanisms that can predict perceived playfulness are only badge and reward $\left(\beta \mathrm{BAD}=-.387^{* *}, \beta \mathrm{REW}=.274^{* *}\right)$. H3a is not supported. Furthermore, perceived playfulness was also found to be a predictor of technostress ( $\beta$ PLA=-.313***), thus confirming H4. A higher level of perceived playfulness was associated with a lower level of technostress. As stated above, not all proposed hypotheses are supported.

Industry and technology trends that make the world of work switch to digital work demand higher education graduates with digital abilities. Also, the constraints experienced by traditional lectures such as time, classrooms, the limited number of participants were the reasons for the development of blended learning. However, the use of technology media in learning raises several problems, such as 'zoom fatigue' [9] and participant engagement [11]. Gamification is a strategy for managing these two problems. The simplest 'Gaming' features to build in a Learning Management System (LMS) are the feedback mechanism and the presentation mechanism. Previous research has found that the two mechanisms can be strong predictors of perceived playfulness [18]. The control system of the presentation mechanism in the progress bar is determined by the three feedback mechanisms. Xp points earned by participants will be accumulated, weighted, and included as a component of task completion. Obtaining badges is closely related to the achievement of certain mastering skills. Participants who already understand a skill will benefit from doing quizzes and assignments. Rewards given in the 'Level Up!' scheme is the accumulation of scores on quizzes and assignments. Badges and rewards can be strong predictors for the progress bar.

$\mathrm{Nah}$, et al. [33] found that the number of experience points gained correlates with the assignment score and the overall score. Educational Badges are designed as an alternative assessment and award that can increase learner motivation [34]. Motivated students will complete lectures according to the timeline and shown in the progress bar. Gamification also makes the learning system more engaging and challenging for students. Giving badges to students who perform well is an example often done [18]. This will give badge recipients pride and increase the motivation of other participants. However, it should be underlined that badges significantly reduce students' perceived playfulness. The methods of using badges vary widely in the real world of the game, so it is possible that the procedure for obtaining badges on this LMS is not appropriate.

Time, place, and number of participants that become obstacles to conventional learning can be solved by e-Learning. Gamification concepts can increase the low level of user involvement in the Learning Management System (LMS) which makes interactions less optimal [35]. In particular, gamification in the learning system is an effective way to fix problems related to time constraints and student pressure [8]. Thus, gamification is able to improve the learning environment to be fun and enjoyable [11]. The build-in gamification technique in non-game applications has been studied to have a positive impact on users. Previous research examined the effect of gamification on participant motivation [13], enjoyment [36], and user engagement [20]. The various positive effects that the participants had had were confirmed. Perceived playfulness is obtained by course participants after participating in learning using Learning Management Systems (LMS) media with gamification features. All gamification features are able to give participants playfulness, except for the point and badge features. Taking quizzes and assignments to earn points and badges is probably the reason why these two features do not affect. Online activities can provide a favorable influence on work that students do independently [37]. Students have positive thoughts on gamification and 
they experience increased achievement in learning [38]. Su's research [36] results become a paradigm for future academic gamification research. De-Marcos, et al. [39] found that gamification plugins used in the learning management system performed better than traditional e-learning approaches in terms of academic achievement for practical tasks. It provides evidence that the development and design of gamification learning content are very important. Gamification makes students feel comfortable when interacting with the learning management system so that it can reduce stress and tension overusing the system.

\section{CONCLUSION}

The demand to apply blended learning in higher education raises the issue of increasing the success of this mixed learning. The intensity of the use of technology can increase student stress and tension. In addition, there are still doubts about the students' motivation and engagement in the Learning Management System (LMS). Gamification is a way out for the same case on other platforms, such as business, marketing, and social media. The research found that the game mechanism implanted in the LMS was able to increase the playfulness of the participants. Besides, this perceived playfulness can reduce the level of technostress in students. The use of the gamification feature has proven to increase the benefits of non-game technology. This study discloses that it can work in learning-related information systems. It becomes an enhancement for system developers to realize that the game-features should be optimized in an LMS. It not only provides enjoyment for the students but also able to reduce stress arising from interactions with technology.

The limitation of this study is that the sample is still relatively small. Further research can use the Massive Online Open Course (MOOCs) media so that a larger sample can be obtained. This research has a practical impact based on user pleasure which can reduce stress levels, reduce user resistance, and increase the effectiveness of technology implementation. The software developer should be considered about technostress factors to increase user acceptance and reduce resistance. System developers should consider using the gamification feature in their applications.

\section{REFERENCES}

[1] J. Lazar, J. H. Feng, and H. Hochheiser, Research Methods in Human-Computer Interaction. Wiley Publishing, 2017.

[2] E. B. Pullins, T. S. Ragu-Nathan, and M. Tarafdar, "Technostress: Negative effect on performance and possible Mitigations," Inf. Syst. J., vol. 25, no. 2, pp. 103-132, 2015, doi: 10.1111/isj.12042.

[3] T. S. Ragu-Nathan, M. Tarafdar, B. S. Ragu-Nathan, and Q. Tu, "The Consequences of Technostress for End Users in Organizations: Conceptual Development and Validation," Inf. Syst. Res., vol. 19, no. 4, pp. 417-433, 2008, doi: 10.1287/isre.1070.0165.

[4] S. O. Ansah, J. Q. Azasoo, and I. N. Adu, "Understanding The Effects of Techno-stress on The Performance of Banking Staff," Int. J. Bus. Contin. Risk Manag., vol. 6, no. 3, p. 222, 2016, doi: 10.1504/ijbcrm.2016.079010.

[5] M. Tarafdar, Q. Tu, T. S. Ragu-Nathan, and B. S. Ragu-Nathan "Crossing to the Dark Side: Examining Creators, Outcomes, and Inhibitors of Technostress," Commun. ACM, vol. 54, no. 9, pp. 113-120, Sep. 2011, doi: 10.1145/1995376.1995403.

[6] D. R. Garrison and H. Kanuka, "Blended learning: Uncovering its transformative potential in higher education," Internet High. Educ., vol. 7, no. 2, pp. 95-105, 2004, doi: 10.1016/j.iheduc.2004.02.001.

[7] C. Williams, "Learning On-line: A review of recent literature in a rapidly expanding field," J. Furth. High. Educ., vol. 26, no. 3, pp. 263-272, 2002, doi: 10.1080/03098770220149620.

[8] A. Sharunova, A. Ead, C. Robson, M. Afaq, and P. Mertiny, "Blended learning by gamification in a second-year introductory engineering design course," ASME Int. Mech. Eng. Congr. Expo. Proc., vol. 5, pp. 0-7, 2018, doi: 10.1115/IMECE2018-86879.

[9] F. Liz and M. W. Duffy, "How to Combat Zoom Fatigue," Harvard Business Review, 2020. [Online]. Available: https://hbr.org/2020/04/how-to-combat-zoom-fatigue.

[10] A. Richter, "Locked-down digital work," Int. J. Inf. Manage., vol. 55, 2020, doi: 10.1016/j.ijinfomgt.2020.102157.

[11] F. L. Khaleel, N. S. Ashaari, T. S. M. T. Wook, and A. Ismail, "User-enjoyable learning environment based on Gamification elements," I4CT 2015 - 2015 2nd Int. Conf. Comput. Commun. Control Technol. Art Proceeding, 2015, pp. 221-226, doi: 10.1109/I4CT.2015.7219570.

[12] S. Deterding, "Gamification; Designing for Motivation," Interactions, vol. 19, no. 4, pp. 14-17, 2012, doi: $10.1145 / 2212877.2212883$

[13] J. C. Burguillo, "Using game theory and Competition-based Learning to stimulate student motivation and performance," Comput. Educ., vol. 55, no. 2, pp. 566-575, 2010, doi: 10.1016/j.compedu.2010.02.018.

[14] A. Bhimani and L. Willcocks, "Digitisation, 'Big Data' and the transformation of accounting information," Account. Bus. Res., vol. 44, no. 4, pp. 469-490, 2014, doi: 10.1080/00014788.2014.910051.

[15] K. Corsi, D. Mancini, and G. Piscitelli, "The Integration of Management Control Systems Through Digital Platforms: A Case Study," in K. Corsi, N. Castellano, R. Lamboglia, D. Mancini, eds., Reshaping Accounting and Management Control Systems. Lecture Notes in Information Systems and Organisation. Springer, Cham, 2019, pp. 131-151, doi: 10.1007/978-3-319-49538-5. 
[16] P. Spagnoletti, A. Resca, and G. Lee, "A design theory for digital platforms supporting online communities: A multiple case study,” J. Inf. Technol., vol. 30, pp. 364-380, 2015, doi: 10.1057/jit.2014.37.

[17] D. Dicheva, C. Dichev, G. Agre, and G. Angelova, "Gamification in Education: A Systematic Mapping Study," $J$. Educ. Technol. Soc., vol. 21, no. 1, pp. 152-154, 2018.

[18] D. Codish and G. Ravid, "Academic Course Gamification: The Art of Perceived Playfulness," Interdiscip. J. eSkills Lifelong Learn., vol. 10, pp. 131-151, 2014, doi: 10.28945/2066.

[19] A. Anderson, D. Huttenlocher, J. Kleinberg, and J. Leskovec, "Steering user behavior with badges," $W W W 2013$ Proc. 22nd Int. Conf. World Wide Web, 2013, pp. 95-105, doi: 10.1145/2488388.2488398.

[20] P. Denny, "The effect of virtual achievements on student engagement," Conf. Hum. Factors Comput. Syst. - Proc., 2013, pp. 763-772, doi: 10.1145/2470654.2470763.

[21] K. Kim and H. Park, "The Effect of Technostress on Information Technology Acceptance," J. Theor. Appl. Inf. Technol., vol. 96, no. 24, pp. 8300-8312, 2018.

[22] A. Ioannou and A. Papazafeiropoulou, "Using IT Mindfulness to Mitigate the Negative Consequences of Technostress," AMCIS 2017 - Am. Conf. Inf. Syst. A Tradit. Innov., vol. 2017, Aug. 2017.

[23] J. B. Thatcher, R. T. Wright, H. Sun, T. J. Zagenczyk, and R. Klein, "Mindfulness in Information Technology Use: Definitions, Distinctions, and a New Measure," MIS Q., vol. 42, no. 3, pp. 831-847, 2018, doi: 10.25300/MISQ/2018/11881.

[24] R. Ayyagari, V. Grover, and R. Purvis, "Technostress: Technological Antecedents and Implications," MIS Q., vol. 35, no. 4, pp. 831-858, 2011.

[25] J. P. Costa, R. R. Wehbe, J. Robb, and L. E. Nacke, "Time's up: Studying leaderboards for engaging punctual behaviour," ACM Int. Conf. Proceeding Ser., 2013, pp. 26-33, doi: 10.1145/2583008.2583012.

[26] J. Chang and H. Wei, "Exploring Engaging Gamification Mechanics in Massive Online Open Courses," J. Educ. Technol. Soc., vol. 19, no. 2, pp. 177-203, 2016.

[27] H. C. L. Hsieh and H. H. Yang, "Incorporating gamification into website design to facilitate effective communication," Theor. Issues Ergon. Sci., vol. 21, no. 1, pp. 89-111, 2020, doi: 10.1080/1463922X.2019.1645920.

[28] J. Hulland, "Use of partial least squares (PLS) in strategic management research: A review of four recent studies," Strateg. Manag. J., vol. 20, no. 2, pp. 195-204, 1999. [Online]. Available: http://www.jstor.org/stable/3094025.

[29] R. P. Bagozzi and Y. Yi, "On the evaluation of structural equation models," J. Acad. Mark. Sci., vol. 16, no. 1, pp. 74-94, 1988, doi: 10.1007/BF02723327.

[30] J. W. Moon and Y. G. Kim, "Extending the TAM for a World-Wide-Web context," Inf. Manag., vol. 38, no. 4, pp. 217-230, 2001, doi: 10.1016/S0378-7206(00)00061-6.

[31] C. Fornell and F. L. Bookstein, "Two Structural Equation Models: LISREL and PLS Applied to Consumer ExitVoice Theory,” J. Mark. Res., vol. 19, no. 4, p. 440, 1982, doi: 10.2307/3151718.

[32] J. F. Hair, C. M. Ringle, and M. Sarstedt, "PLS-SEM: Indeed a silver bullet," J. Mark. Theory Pract., vol. 19, no. 2, pp. 139-152, 2011, doi: 10.2753/MTP1069-6679190202.

[33] F. F.-H. Nah, Q. Zeng, V. R. Telaprolu, A. P. Ayyappa, and B. Eschenbrenner "Gamification of Education: A Review of Literature," in International Conference on HCI in Business. Springer, Cham, 2014, vol. 8527, pp. 401-409, doi: 10.1007/978-3-319-07293-7_39.

[34] S. Abramovich, C. Schunn, and R. M. Higashi, "Are badges useful in education?: It depends upon the type of badge and expertise of learner," Educ. Technol. Res. Dev., vol. 61, no. 2, pp. 217-232, 2013, doi: 10.1007/s11423-0139289-2.

[35] A. Y. Utomo, A. Amriani, A. F. Aji, F. Wahidah, and K. Junus, "Gamified E-learning model based on community of inquiry," Int. Conf. Adv. Comput. Sci. Inf. Syst., 2014, pp. 474-480.

[36] C. H. Su, "The effects of students' motivation, cognitive load and learning anxiety in gamification software engineering education: a structural equation modeling study," Multimed. Tools Appl., vol. 75, no. 16, pp. 10013-10036, 2016, doi: 10.1007/s11042-015-2799-7.

[37] M. V. López-Pérez, M. C. Pérez-López, and L. Rodríguez-Ariza, "Blended learning in higher education: Students' perceptions and their relation to outcomes," Comput. Educ., vol. 56, no. 3, pp. 818-826, 2011, doi: 10.1016/j.compedu.2010.10.023.

[38] Z. Turan, Z. Avinc, K. Kara, and Y. Goktas, "Gamification and education: Achievements, cognitive loads, and views of students,” Int. J. Emerg. Technol. Learn., vol. 11, no. 7, pp. 64-69, 2016, doi: 10.3991/ijet.v11i07.5455.

[39] L. De-Marcos, A. Domínguez, J. Saenz-De-Navarrete, and C. Pagés, "An empirical study comparing gamification and social networking on e-learning," Comput. Educ., vol. 75, pp. 82-91, 2014, doi: 10.1016/j.compedu.2014.01.012. 